\title{
From pests to tests: training rats to diagnose tuberculosis
}

\author{
Lena Fiebig $^{1,2}$, Negussie Beyene ${ }^{1,2,3}$, Robert Burny ${ }^{4}$, Cynthia D. Fast $^{1}$, \\ Christophe Cox $^{1,2}$ and Georgies F. Mgode ${ }^{1,5}$
}

Affiliations: ${ }^{1}$ APOPO (Anti-Persoonsmijnen Ontmijnende Product Ontwikkeling; in English, Anti-Personnel Landmines Detection Product Development) Training and Research Centre, Sokoine University of Agriculture, Morogoro, Tanzania. ${ }^{2}$ Dept of Biology, University of Antwerp, Antwerp, Belgium. ${ }^{3}$ AHRI-APOPO TB Research Project, Armauer Hansen Research (AHRI) Institute, Addis Ababa, Ethiopia. ${ }^{4}$ APOPO TB Project, University Eduardo Mondlane (UEM), Maputo, Mozambique. ${ }^{5}$ Pest Management Centre, Africa Centre of Excellence for Innovative Rodent Pest Management and Biosensor Technology Development, Sokoine University of Agriculture, Morogoro, Tanzania.

Correspondence: Lena Fiebig, APOPO Training and Research Centre, Sokoine University of Agriculture, PO 3078, Morogoro, Tanzania. E-mail: lena.fiebigdapopo.org

@ERSpublications

It's time... to find and treat all patients with TB. Rats may have a say in research towards better diagnostic tests. http://bit.ly/2Rioa9N

Cite this article as: Fiebig L, Beyene N, Burny R, et al. From pests to tests: training rats to diagnose tuberculosis. Eur Respir J 2020; 55: 1902243 [https://doi.org/10.1183/13993003.02243-2019].

2020 is the year of the rat. The rat is the first of the 12 Chinese zodiac signs, and represents spirit, alertness, flexibility and vitality. In respiratory medicine, we may think of rats as vectors for diseases, such as pulmonary forms of hantavirus disease or leptospirosis, and pneumonic plague. Rodent control is thus part of hygiene guidelines and the International Health Regulations. And yet, the rat's keen sense of smell has led to its incredible career as a living tuberculosis (TB) detector.

The TB detection rat journey began with an idea in Tanzania in 2001, roughly 120 years after the TB-causing Mycobacterium tuberculosis was discovered by microscopy and bacterial culture. African giant pouched rats (Cricetomys ansorgei) had already been successfully trained using positive reinforcement to find explosives [1]. So, the question arose if they could do more for humanity by helping to also combat disease. But how would the rats use their noses to find bacteria or otherwise sniff out TB patients? For centuries, olfaction had already informed diagnostics in medical practices, e.g. in detecting metabolic issues such as ketoacidosis or tissue decay such as gangrene [2]. In the Flemish common language, the word tering, which etymologically refers to the smell of tar, is used for TB. The advent of chromatographic techniques allows characterisation of the organic compounds causing odours.

Researchers from the Tanzanian National Institute for Medical Research (NIMR), the Sokoine University of Agriculture (SUA) and the Belgium non-profit APOPO, found this evidence intriguing enough to train African giant pouched rats with the odour of heat-inactivated bacteriological culture and later, heat-inactivated human sputum samples, to find out if the rats could identify pulmonary TB. The evaluation setting was, and still is, a locally made aluminium cage to present ten samples in a row to the rat (figure 1).

A few years later, the concept was proven: rats can smell TB! [3] Further evaluation followed [4], and over the years, performance characteristics were defined through scientific studies (table 1). The results suggested that the rats are unique in their very high speed, throughput, sensitivity (considering that local 
FIGURE 1 A trained rat indicating a positive sample by keeping the nose in the sniffing hole with the test sample underneath in a 10-hole evaluation cage.

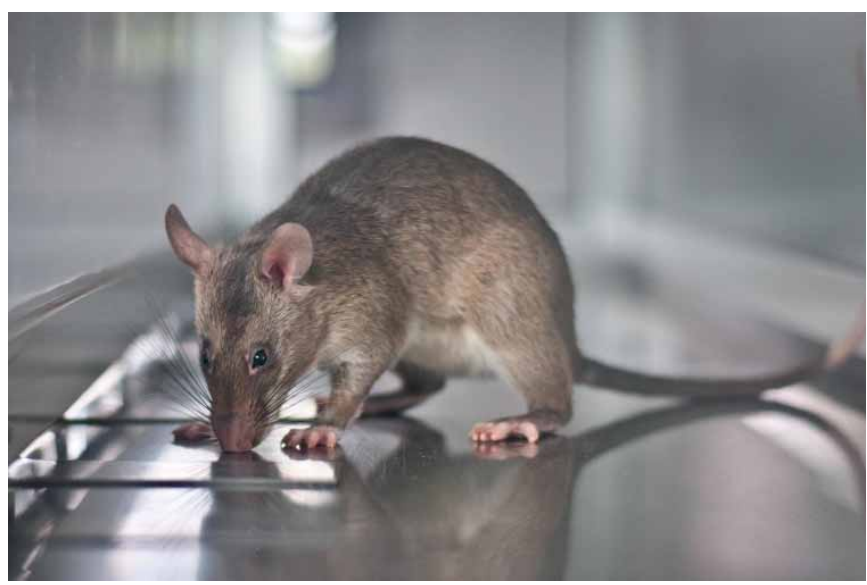

sputum smear microscopy had a sensitivity of about 37\% compared to culture) [5], and low modelled cost of just USD 1.13 per sample tested. The main cost driver is staff, which comes along with the creation of local employment opportunities.

Yet, the puzzle remained: what are the rats actually smelling in the sample? Analytical chemistry conducted in partnership with the Max Planck Institute for Infection Biology in Berlin and the Technical University of Braunschweig in Germany resulted in the discovery of TB-specific volatile organic compound (VOC) patterns [11]. The VOC patterns were found to be distinct from those emitted from cultures of non-tuberculosis mycobacteria species or other bacteria that look similar under the microscope, such as Nocardia and Rhodococcus. While no single compound was alone predictive of TB, a bouquet of VOCs in varying composition, quantity, and overlap were found [11-13]. This research provided additional empirical evidence of a detectable TB-specific scent, but also highlighted the challenge in identifying reliable VOC biomarkers for developing olfactory-based diagnostic tools, such as e-noses. In contrast, rats as living biosensors do not need a priori knowledge of the compounds. They rely on odour pattern recognition, similar to how humans recognise the scent of coffee without embarking on a biochemistry study.

To reliably recognise an odour, it takes behavioural training involving positive reinforcement and discrimination learning [3, 14]. It also requires roughly 3000 samples for the rat to form a concept of the TB odour across its various expressions (i.e. samples that differ in bacterial load and that have been collected from patients of all ages and sexes) while preventing the cunning rat from using extraneous cues that might otherwise covary with positive samples (such as comorbid disease or how the samples are handled at the clinic) and circumvent detection of new TB cases. Moreover, the training and research depends on standard TB tests on the samples for reference.

These requirements raised the question if clinics and patients who contribute samples for research could directly benefit from the additional investigation of their samples. Upon ethical clearance, this idea was evaluated in the field, starting with four partnering healthcare facilities in Tanzania. In that model, facilities share human sputum samples after completing their routine diagnostics with sputum smear microscopy. The rats re-evaluate the heat-inactivated samples at a central research laboratory. Samples initially tested negative by healthcare facilities that are indicated by at least one trained rat undergo confirmatory TB testing in the central research laboratory. Confirmation test results (initially based on ZN and LED-FM microscopy on concentrated smears, and, since 2018, increasingly by molecular testing) are reported back to the healthcare facilities, which provide directly observed TB therapy. This model increased detection of bacteriologically confirmed pulmonary TB cases by an average 40\% [10] and an even more impressive 68\% among young children [15]. Additionally detected cases have mostly low bacterial counts [15]. The results piqued the interest of healthcare facilities and health authorities and, over time, more clinics volunteered to join the research in Tanzania. From there, the model was replicated in Maputo, Mozambique together with the Eduardo Mondlane University (in 2013) and Addis Ababa, Ethiopia in partnership with the Armauer Hansen Research Institute (in 2018).

Nonetheless, pre-treatment loss-to-follow-up remained a barrier to achieving health impact. It is well known in TB control that if newly diagnosed TB patients cannot be treated effectively, diagnostic efforts are of little value. Many patients who tested positive (by a standard diagnostic test) did not return to clinics to receive their results and begin treatment. Thus, what began as rat research evolved into health service research with the design of an integrated model. The model includes rats as a test for research use 
TABLE 1 Current performance characteristics of trained tuberculosis (TB) detection rats

\begin{tabular}{|c|c|c|c|c|c|c|c|}
\hline Characteristic [6] & \multicolumn{7}{|l|}{ Study results } \\
\hline Goal & \multicolumn{7}{|l|}{ Triage test } \\
\hline Target population & \multicolumn{7}{|c|}{ Adults and children with signs and symptoms of pulmonary TB } \\
\hline Setting & \multicolumn{7}{|c|}{ Semi-centralised laboratories, sample referral from primary healthcare facility level } \\
\hline \multirow{7}{*}{$\begin{array}{l}\text { Diagnostic accuracy for } \\
\text { detection of pulmonary TB }\end{array}$} & Population group & Sensitivity \% & Specificity \% & Reference test & Rats in team & Indication threshold ${ }^{\#}$ & Reference \\
\hline & $\begin{array}{l}\text { Patients with presumptive TB (all), } \\
\text { sample-wise study ( } \mathrm{n}=819)\end{array}$ & 86.6 & 89.1 & Culture & 2 & $\geqslant 1$ & WeETJens et al. [3] \\
\hline & $\begin{array}{l}\text { Patients with presumptive TB (all), } \\
\text { patient-wise study }(n=456)\end{array}$ & 81.9 & 64.6 & Multiplex PCR & 10 & $\geqslant 2$ & MaHONEY et al. [7] \\
\hline & $\begin{array}{l}\text { Patients with presumptive TB (all), } \\
\text { patient-wise ( } \mathrm{n}=237)\end{array}$ & 71.6 & 59.4 & Culture & 7 & $\geqslant 1$ & ReITHER et al. [8] \\
\hline & $\begin{array}{l}\text { Patients with presumptive TB (all), } \\
\text { patient-wise }(\mathrm{n}=765)\end{array}$ & 81.8 & 40.0 & Xpert MTB/Rif & 11 & $\geqslant 1$ & MULDER et al. [9] \\
\hline & $\begin{array}{l}\text { Patients with presumptive TB lall), } \\
\text { patient-wise ( } \mathrm{n}=771)\end{array}$ & 75.1 & 40.6 & Culture & 11 & $\geqslant 1$ & MULDER et al. [9] \\
\hline & $\begin{array}{l}\text { Patients with presumptive TB (PLHIV), } \\
\text { patient-wise }(n=264)\end{array}$ & 70.8 & 36.4 & Culture & 11 & $\geqslant 1$ & MULDER et al. [9] \\
\hline Manual preparation of samples & \multicolumn{7}{|c|}{ None, yet currently heat inactivation of closed sputum containers } \\
\hline Time to result & \multicolumn{7}{|c|}{3 s per indication } \\
\hline Throughput & \multicolumn{7}{|c|}{100 samples in 20 minutes or less, $>200$ per day [10] } \\
\hline $\begin{array}{l}\text { Maintenance and calibration } \\
\text { Internal quality control }\end{array}$ & \multicolumn{7}{|c|}{$\begin{array}{l}\text { Rats reliably evaluate sputum samples with only } 8 \text { or less rewarded encounters with a sample from a known TB patient per evaluation session } \\
\text { Internal controls included in evaluation set-up }\end{array}$} \\
\hline Operating temperature & \multicolumn{7}{|c|}{ Rats are well-adapted to the sub-Saharan climate and can comfortably work with temperatures between $21^{\circ}$ and $34^{\circ} \mathrm{C}$} \\
\hline $\begin{array}{l}\text { Result capturing, documentation, } \\
\text { data display }\end{array}$ & \multicolumn{7}{|c|}{$\begin{array}{l}\text { Manual read and entry (though fully automated evaluation cage version now available) in custom laboratory database from which reports are } \\
\text { generated }\end{array}$} \\
\hline Price of individual test & \multicolumn{7}{|c|}{$\begin{array}{l}\text { USD } 1.13 \text { per sample tested using a team of rats (micro-costing considering staff, building space, equipment, reagents, chemicals, consumables } \\
\text { and overhead in Tanzania, unpublished data) }\end{array}$} \\
\hline
\end{tabular}


only but goes far beyond in 1) working towards results turnaround within $24 \mathrm{~h}$ by moving the research laboratory closer to the patients, establishing a motorbike courier sample referral network, and (re) evaluating samples in evening hours; and 2) partnering with community-based organisations, like MKUTA in Tanzania (who employ TB survivors as community health workers and volunteers) and Kenguelekezé in Mozambique, to link patients to care through education and tracking. Integrating these elements markedly raised linkage to care from about $55 \%$ to around $80 \%[16,17]$.

Today, the research across three African countries has resulted in more than 16000 additional bacteriological TB diagnoses. TB detection rats are one of the most advanced medical applications of animal scent detection [18]. A firm empirical foundation with a rich body of experience with test development and service delivery has resulted, and there is unabated interest in the approach reflected by growing partnerships. Nonetheless, scepticism on a greater acceptability and scalability of animal-based TB detection system remains [19], and there is need to further optimise rat performance to achieve triage test accuracy criteria defined in international target product profiles, i.e. of $>90 \%$ sensitivity and $>70 \%$ specificity as required for WHO approval [7]. Finally, relying on sputum as a sample material may not be the end of the story.

What next? The year of the rat will be an exciting one for our rats: they will meet another living biosensor, Joy Milne, the woman who can smell Parkinson's disease, and the team from Manchester Institute for Biotechnology $[20,21]$ to jointly investigate a range of new sample materials, including saliva, urine and breath. The study will use scent detection and analytical chemistry synergistically to inform the refinement of TB detection rats as well as synthetic devices. The journey continues... it's time for simpler TB tests and to find and treat all patients with TB.

Acknowledgements: The authors thank all study participants, clinicians, laboratory and rat handler teams, as well as all partners and donors who enabled the research into training and using TB detection rats. Main partners include the Sokoine University of Agriculture, the National Institute for Medical Research, MKUTA, and the National TB and Leprosy Programme in Tanzania; the University Eduardo Mondlane, the National Institute of Health, Associação Kenguelekezé, the Maputo City Health Authorities and the National TB Program in Mozambique; the Armauer Hansen Research Institute, the German Leprosy and TB Relief Association, the Prison Health Authorities and the National TB Program of Ethiopia; as well as the Technical University Braunschweig and Max Planck Institute for Infection Biology in Germany, and the University of Antwerp, Belgium.

Conflict of interest: L. Fiebig reports grants from the Carraresi Foundation, UBS Optimus Foundation (UBS OF), UKAID through the Human Development Innovation Fund in Tanzania (HDIF), Government of Flanders (GoF), Skoll Foundation (Skoll) and Elton John Aids Foundation (EJAF) during the conduct of the study; and is an employee of APOPO TB detection, the developer of the described test technology. N. Beyene reports grants from Skoll, EJAF, the Carraresi Foundation, UKAID/HDIF and UBS OF during the conduct of the study; and is affiliated to APOPO TB detection; APOPO is the developer of TB detection rat technology. R. Burny reports grants from GoF and the Carraresi Foundation during the conduct of the study; and is managing the TB operations of APOPO in Mozambique, which include rat detection technology. C.D. Fast reports grants from the Carraresi Foundation, UBS OF, UKAID/HDIF, EJAF, Skoll, GoF, and the Philanthropic Foundation of the Firmenich Family during the conduct of the study; and is an employee of APOPO, the organisation that develops the TB detection rat technology. C. Cox reports reports grants from the Carraresi Foundation, UBS OF, UKAID/HDIF, EJAF, Skoll, GoF, and the Philanthropic Foundation of the Firmenich Family during the conduct of the study; and is co-founder and employee of APOPO, the developer of the TB detection rats. G.F. Mgode reports grants from UKAID/HDIF, UBS OF, and the Carraresi Foundation during the conduct of the study, and is affiliated to APOPO, the developer of the TB detection rat technology.

Support statement: Main financial support has been granted by the Government of Flanders, the Carraresi Foundation, the UBS Optimus Foundation, UKAID through the Human Development Innovation Fund in Tanzania, the Skoll Foundation and the Elton John Aids Foundation. Funding information for this article has been deposited with the Crossref Funder Registry.

\section{References}

1 Cox C, Weetjens B, Machangu R, et al. Rats for demining: an overview of the APOPO program. Proceedings of the Eudem Conference on humanitarian landmine detection technologies, 2004. Available from: https://www.apopo.org/ pdfs/Scientific\%20Publications/Cox_et_al_Rats_for_demining_an_overview_of_the_APOPO_program.pdf

2 Bijland LR, Bomers MK, Smulders YM. Smelling the diagnosis: a review on the use of scent in diagnosing disease. Neth J Med 2013; 71: 300-307.

3 Weetjens B, Mgode G, Machang'u R, et al. African pouched rats for the detection of pulmonary tuberculosis in sputum samples. Int J Tuberc Lung Dis 2009; 13: 737-743.

4 Poling A, Mahoney A, Beyene N, et al. Using giant African pouched rats to detect human tuberculosis: a review. Pan Afr Med J 2015; 21: 333.

5 Mfinanga GS, Ngadaya E, Mtandu R, et al. The quality of sputum smear microscopy diagnosis of pulmonary tuberculosis in Dar es Salaam, Tanzania. Tanzan Health Res Bull 2007; 9: 164-168.

6 World Health Organization. High-priority Target Product Profiles for New Tuberculosis Diagnostics: Report of a Consensus Meeting. 28-29 April 2014, Geneva, Switzerland. WHO/HTM/TB/2014.18

7 Mahoney A, Weetjens B, Cox C, et al. Pouched rats' detection of tuberculosis in human sputum: comparison to culturing and polymerase chain reaction. Tuberc Res Treat 2012; 2012: 716989. 
8 Reither K, Jugheli L, Glass TR, et al. Evaluation of giant African rats for detection of pulmonary tuberculosis in patients from a high-endemic setting. PLoS ONE 2015; 10: e0135877.

9 Mulder C, Mgode GF, Ellis H, et al. Accuracy of giant African pouched rats for diagnosing tuberculosis: comparison with culture and Xpert ${ }^{\oplus}$ MTB/RIF. Int J Tuberc Lung Dis 2017; 21: 1127-1133.

10 Mulder C, Mgode G, Reid SE. Tuberculosis diagnostic technology: an African solution ... think rats. Afr J Lab Med 2017; 6: 420.

11 Mgode GF, Weetjens BJ, Nawrath T, et al. Mycobacterium tuberculosis volatiles for diagnosis of tuberculosis by Cricetomys rats. Tuberculosis (Edinb) 2012; 92: 535-542.

12 Mgode GF, Weetjens BJ, Cox C, et al. Ability of Cricetomys rats to detect Mycobacterium tuberculosis and discriminate it from other microorganisms. Tuberculosis (Edinb) 2012; 92: 182-186.

13 Mgode GF, Weetjens BJ, Nawrath T, et al. Diagnosis of tuberculosis by African giant pouched rats and confounding impact of pathogens and microflora of the respiratory tract. J Clin Microbiol 2012; 50: 274-280.

14 Poling A, Weetjens B, Cox C, et al. Tuberculosis detection by giant African pouched rats (Cricetomys gambianus). Behav Anal 2011; 34: 47-54.

15 Mgode GF, Cox CL, Mwimanzi S, et al. Pediatric tuberculosis detection using trained African giant pouched rats. Pediatr Res 2018; 84: 99-103.

16 Soka J, Fiebig L, Cox C, et al. APOPO's TB detection: results in $24 \mathrm{~h}$ and patient tracking improve linkage to care, Tanzania, 2014-2017. Poster presentation at the 49th World Conference of the IUTLD, The Hague, Netherlands. Available from: http://www.hdif-tz.org/wp-content/uploads/sites/11/2018/10/2018_Union-conference-poster_ Apopo_final.pdf

17 Burny R, Manhiça I, Pedro Magaia de Abreu A, et al. Rapid TB diagnostic service and community action to FIND.TREAT.ALL\#EndTB - experiences from Maputo, Mozambique, 2013-2018. Public Health Action 2020; in press.

18 Edwards TL, Browne C, Schoon A, et al. Animal olfactory detection of human diseases: Guidelines and systematic review. J Vet Behavior: Clinical Applications and Research 2017; 20: 59-73.

19 Pai M. Do rats pass the sniff test? Int J Tuberc Lung Dis 2017; 21: 1089-1090.

20 Morgan J. Joy of super smeller: sebum clues for PD diagnostics. Lancet Neurol 2016; 15: 138-139.

21 Trivedi DK, Sinclair E, Xu Y, et al. Discovery of volatile biomarkers of Parkinson's disease from sebum. ACS Cent Sci 2019; 5: 599-606. 